\title{
Uji Degradasi Pewarna Rhodamine B oleh Senyawa Aurivillius Lapis Dua $\mathrm{SrBi}_{2} \mathrm{Ta}_{2} \mathrm{O}_{9}$
}

\section{Photocatalytic Degradation of Rhodamine B by Two-Layer Aurivillius Compound $\mathrm{SrBi}_{2} \mathrm{Ta}_{2} \mathrm{O}_{9}$}

\author{
Usman Ali Rouf ${ }^{1}$, Erna Hastuti ${ }^{2}$, Anton Prasetyo ${ }^{1, *}$ \\ ${ }^{1}$ Program Studi Kimia, Fakultas Sains dan Teknologi, Universitas Islam Negeri Maulana Malik Ibrahim Malang, \\ Jalan Gajayana No. 50, Malang, 65144 \\ ${ }_{2}^{2}$ Program Studi Fisika, Fakultas Sains dan Teknologi, Universitas Islam Negeri Maulana Malik Ibrahim Malang, \\ , Jalan Gajayana No. 50, Malang, 65144 \\ *E-mail: anton@ kim.uin-malang.ac.id
}

DOI: https://doi.org/10.26874/jkk.v4i1.76

Received: 30 March 2021, Revised: 30 May 2021, Accepted: 30 May 2021, Online: 31 May 2021

\begin{abstract}
Abstrak
Senyawa Aurivillius lapis dua $\mathrm{SrBi}_{2} \mathrm{Ta}_{2} \mathrm{O}_{9}$ dilaporkan berpotensi sebagai material fotokatalis sehingga dapat digunakan untuk mendegradasi limbah zat warna. Pada penelitian ini telah disintesis senyawa $\mathrm{SrBi}_{2} \mathrm{Ta}_{2} \mathrm{O}_{9}$ dengan metode reaksi keadaan padatan dan selanjutnya dilakukan uji kemampuan dalam mendegradasi zat warna rhodamine B. Difraktogram menunjukkan bahwa, telah terbentuk senyawa $\mathrm{SrBi}_{2} \mathrm{Ta}_{2} \mathrm{O}_{9}$ dengan grup ruang $\mathrm{A} 2_{1} \mathrm{am}$ dan tidak ditemukan adanya pengotor. Gambar scanning electron microscopy (SEM) menunjukkan bahwa partikel $\mathrm{SrBi}_{2} \mathrm{Ta}_{2} \mathrm{O}_{9}$ berbentuk plate-like dan teraglomerasi. Spektrum diffuse reflectance spectroscopy menunjukkan bahwa $\mathrm{SrBi}_{2} \mathrm{Ta}_{2} \mathrm{O}_{9}$ mempunyai energi celah pita sebesar 3,15 eV ( 393,60 nm). Hasil uji degradasi larutan rhodamine B menunjukkan bahwa kemampuan $\mathrm{SrBi}_{2} \mathrm{Ta}_{2} \mathrm{O}_{9}$ dalam mendegradasi adalah 8,6\% selama 80 menit. Kemampuan degradasi yang rendah dikarenakan ukuran partikel $\mathrm{SrBi}_{2} \mathrm{Ta}_{2} \mathrm{O}_{9}$ relatif besar dan dalam keadaan teraglomerasi.
\end{abstract}

Kata kunci: aglomerasi, fotokatalis, rhodamine $\mathrm{B}, \mathrm{SrBi}_{2} \mathrm{Ta}_{2} \mathrm{O}_{9}$, ukuran partikel.

\begin{abstract}
The two-layer Aurivillius compound $\mathrm{SrBi}_{2} \mathrm{Ta}_{2} \mathrm{O}_{9}$ has been known as a potential photocatalyst as results can be applied to degrade dye waste. In this research, the $\mathrm{SrBi}_{2} \mathrm{Ta}_{2} \mathrm{O}_{9}$ compound was synthesized using a solid-state reaction and then measured to degrade rhodamine $B$ dye. The diffractogram showed that the $\mathrm{SrBi}_{2} \mathrm{Ta}_{2} \mathrm{O}_{9}$ compound has formed with space group $\mathrm{A} 2_{1}$ am and there are no impurities. Scanning electron microscopy (SEM) image showed that the shape of $\mathrm{SrBi}_{2} \mathrm{Ta}_{2} \mathrm{O}_{9}$ particles is plate-like and in agglomeration condition. DRS spectrum showed that the bandgap energy of $\mathrm{SrBi}_{2} \mathrm{Ta}_{2} \mathrm{O}_{9}$ is $3.15 \mathrm{eV}$ ( $393.60 \mathrm{~nm}$ ). The rhodamine B solution's degradation test results showed that the sample could degrade $8.6 \%$ rhodamine $\mathrm{B}$ for 80 minutes. The low degradability is due to the particles. $\mathrm{SrBi}_{2} \mathrm{Ta}_{2} \mathrm{O}_{9}$ has a bigger size and also were found agglomeration.
\end{abstract}

Keywords: agglomeration, particle size, photocatalyst, rhodamine $\mathrm{B}, \mathrm{SrBi}_{2} \mathrm{Ta}_{2} \mathrm{O}_{9}$.

\section{Pendahuluan}

Rhodamine B $(\mathrm{RhB})$ merupakan pewarna dari golongan xanthene yang sering digunakan sebagai pewarna dalam industri tekstil, dan industri makanan. $\mathrm{RhB}$ dilaporkan bersifat karsinogenik (penyebab kanker) yang dapat menyebabkan iritasi mata dan kulit, merusak sistem saraf, pernafasan, dan reproduksi. 
Pembuangan limbah zat warna RhB meskipun pada konsentrasi rendah sudah dikategorikan berbahaya karena sifat toksiknya, sehingga tidak boleh dibuang secara bebas [1]. Beberapa metode telah dikembangkan untuk mengurangi kadar limbah RhB diantaranya dengan mikroalga, bioremediasi, presipitasi kimia, dan membran filtrasi. Namun metode tersebut memiliki kelemahan yaitu (a) proses secara biologi (mikroalga dan bioremediasi) sulit untuk dikendalikan dan terbatas pada pewarna tertentu; (b) proses presipitasi kimia membutuhkan bahan yang banyak sehingga menghasilkan limbah baru; dan (c) pada proses membran filtrasi membutuhkan biaya yang besar [2].

Salah satu teknologi yang dilaporkan memiliki potensi besar untuk penanganan limbah zat warna adalah fotokatalis yang dapat mendegradasi zat warna dengan bantuan foton. Degradasi limbah zat warna dengan teknologi fotokatalis adalah ramah lingkungan karena hanya menghasilkan produk akhir berupa air dan karbon dioksida. Beberapa material yang dilaporkan berpotensi digunakan dalam teknologi fotokatalis adalah $\mathrm{TiO}_{2}$, material berstruktur perovskit, dan Aurivillius [2-6].

Material berstruktur Aurivillius mempunyai rumus umum $\left[\mathrm{Bi}_{2} \mathrm{O}_{2}\right]^{2+}\left[A_{n-1} B_{n} \mathrm{O}_{3 n+1}\right]^{2-}$ yang tersusun atas lapis perovskit dan lapis bismuth. Kation $A$ ditempati oleh kation monovalen $\left(\mathrm{Na}^{+}\right.$, $\left.\mathrm{K}^{+}\right)$, divalen $\left(\mathrm{Ca}^{2+}, \mathrm{Sr}^{2+}, \mathrm{Ba}^{2+}, \mathrm{Pb}^{2+}\right)$ dan trivalen $\left(\mathrm{Bi}^{3+}\right)$, sedangkan kation $B$ ditempati oleh kation dengan elektron valensi tinggi seperti $\mathrm{Ti}^{4+}, \mathrm{Nb}^{5+}$, dan $\mathrm{Ta}^{5+}$ dengan " $n$ " $(1,2,3,4,5 \ldots)$ menunjukkan jumlah lapis perovskit $[7,8]$. Banyak pihak telah melaporkan potensi berbagai jenis material ini sebagai material fotokatalis di antaranya adalah $\mathrm{Bi}_{2} \mathrm{MO}_{6}, \mathrm{Bi}_{2} \mathrm{MoO}_{6}, \mathrm{Bi}_{3} \mathrm{TiNbO}_{9}, \mathrm{Bi}_{4} \mathrm{~V}_{2} \mathrm{O}_{11}$, dan $\mathrm{Bi}_{4} \mathrm{Ti}_{3} \mathrm{O}_{12}$ [9-13]. Mamidi, dkk. (2018) melaporkan bahwa keberadaan elektron pada orbital $6 s \mathrm{Bi}$ di struktur senyawa Aurivillius menurunkan energi celah pita sehingga dapat meningkatkan transfer muatan untuk meningkatkan aktivitas fotokatalitik [14].

$\mathrm{SrBi}_{2} \mathrm{Ta}_{2} \mathrm{O}_{9}(\mathrm{SBT})$ adalah senyawa golongan Aurivillius lapis dua yang dilaporkan berpotensi sebagai material fotokatalis dengan energi celah pita 3,67 eV [15]. Tian, dkk. (2017) melakukan perhitungan teoritis sifat optik dari senyawa SBT dengan menggunakan metode perhitungan the partial and total densities of states (DOS) dan diperoleh hasil bahwa senyawa SBT memiliki energi celah pita sebesar 2,071 eV [16]. Li, dkk. (2008) melaporkan aktivitas fotokatalitik SBT pada proses water splitting dan dilaporkan bahwa
$\mathrm{H}_{2}$ yang terbentuk sebanyak 2,26 mmol dalam 9 jam pertama [15]. Hal ini menunjukkan bahwa senyawa SBT berpeluang digunakan dalam teknologi fotokatalis sehingga bisa dimanfaatkan dalam mendegradasi zat warna RhB. Berdasarkan uraian diatas maka dalam penelitian ini dikaji kemampuan senyawa SBT dalam mendegradasi $\mathrm{RhB}$.

\section{Metode Penelitian}

\subsection{Sintesis SBT}

Dalam penelitian ini menggunakan prekursor: $\mathrm{SrCO}_{3}$ (Sigma-Aldrich), $\mathrm{Bi}_{2} \mathrm{O}_{3}$ (SigmaAldrich), dan $\mathrm{Ta}_{2} \mathrm{O}_{5}$ (Sigma-Aldrich). Metode sintesis yang digunakan adalah metode reaksi keadaan padatan. Seluruh prekursor ditimbang berdasarkan perhitungan stoikiometri dan digerus selama 1 jam dengan ditambahkan aseton supaya lebih homogen, dan kemudian dikalsinasi pada suhu 700,800 , dan $900{ }^{\circ} \mathrm{C}$ selama 6 jam.

\subsection{Karakterisasi}

Sampel yang diperoleh (SBT) dikarakterisasi dengan menggunakan teknik difraksi sinar- $X$ (XRD) (Rigaku Miniflex diffractometer) untuk mengidentifikasi fasa yang terbentuk. Pengukuran dilakukan pada rentang pengukuran $2 \theta\left({ }^{\circ}\right)=3-90$. Difraktogram yang diperoleh selanjutnya direfinement dengan menggunakan program fulproof untuk mendapatkan data kristalografinya. Morfologi partikel dikarakterisasi dengan menggunakan scanning electron microscopy (SEM) (JEOL JSM-6360LA) dengan perbesaran $15.000 \mathrm{x}$, dan diolah dengan menggunakan piranti lunak Image-J untuk mengukur ukuran partikel. Profil serapan sinar oleh sampel diukur dengan menggunakan ultraviolet-visible diffuse reflectance spectroscopy (UV-Vis-DRS) (Thermo Scientific Evolution 220 spectrometer) dengan rentang pengukuran pada 200-1000 nm. Spektrum yang diperoleh diolah dengan persamaan Kubelka-Munk untuk menghitung nilai energi celah pita.

\subsection{Uji Degradasi Zat Warna RhB}

Uji kemampuan SBT dalam mendegradasi zat warna $\mathrm{RhB}$ menggunakan reaktor fotokatalis buatan sendiri dengan volume $64 \mathrm{~cm}^{3}$ dan lampu UV komersial sebanyak 9 buah. Sebelum uji degradasi dilakukan uji kestabilan larutan $\mathrm{RhB}$ $8.10^{-6} \mathrm{M}$ terhadap cahaya pada variasi waktu 0,20 , 40, 60, dan 80 menit. Pengujian degradasi RhB dilakukan dengan cara $100 \mathrm{ml}$ larutan $\mathrm{RhB} 8.10^{-6}$ $\mathrm{M}$ dimasukkan ke dalam gelas kimia dan ditambahkan katalis SBT sebanyak 0,1 gram. 
Setelah itu, campuran tersebut dimasukkan ke dalam reaktor fotokatalis, dan diaduk selama 30 menit tanpa cahaya untuk memastikan terjadi kesetimbangan adsorpsi-desorpsi, kemudian dilakukan penyinaran selama $0,20,40,60,80$ menit. Setelah dilakukan radiasi, larutan didiamkan untuk mengendapkan katalis, dan kemudian diukur serapan cahaya larutan hasil degradasi RhB dengan menggunakan spektrofotometer UV-Vis.

\section{Hasil dan Diskusi}

Difraktogram SBT ditampilkan pada Gambar 1. dan dicocokkan dengan standar SBT pada International Crystallography Standar Data (ICSD) No. 92057 dengan grup ruang $A 2_{1} \mathrm{am}$. Hasil perbandingan menunjukkan bahwa terjadi kesesuaian pola antara difraktogram sampel dengan standar dan ditemukan puncak difraksi khas SBT pada posisi $2 \theta\left({ }^{\circ}\right): 21,8 ; 23,04 ; 25,18$; 28,$98 ; 32,4 ; 35,86 ; 39,76 ; 43,7 ; 46,46 ; 49,08$; 52,$98 ; 55,7$; dan 60,04 . Hal ini menunjukkan bahwa senyawa target (SBT) telah berhasil disintesis dan ketiadaan puncak tambahan menunjukkan bahwa tidak ada fasa pengotor. Difraktogram juga menunjukkan bahwa masih ada noise yang menunjukkan bahwa kristalinitas sampel tidak tinggi. Peneliti lain telah melaporkan bahwa untuk sintesis SBT dengan metode reaksi keadaan padatan membutuhkan suhu $1200^{\circ} \mathrm{C}$ $[15,17]$, sedangkan dalam penelitian ini dilakukan pada suhu yang lebih rendah yaitu $900^{\circ} \mathrm{C}$ sehingga proses pertumbuhan kristalnya masih belum sempurna.

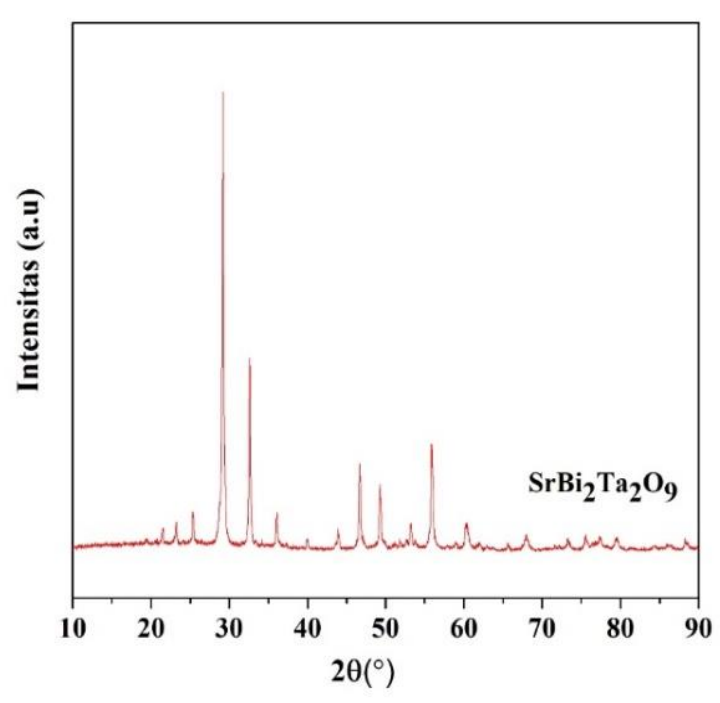

Gambar 1. Difraktogram SBT
Difraktogram SBT direfinement dengan menggunakan program fullproff dan menggunakan data standar ICSD No. 92057 dengan grup ruang $A 2{ }_{1} \mathrm{am}$. Plot refinement ditampilkan pada Gambar 2 dan hasil refinement dirangkum pada Tabel 1 . Nilai $R_{p}$ yang diperoleh adalah sebesar $20,5 \%$, sedangkan nilai $R_{w p}$ yang diperoleh adalah sebesar $19,8 \%$. Nilai $R_{p}$ dan $R_{w p}$ yang diperoleh menunjukkan bahwa difraktogram sampel mempunyai kecocokan dengan difraktogram standar sehingga dapat dinyatakan bahwa sampel mempunyai grup ruang $A 2_{1} \mathrm{am}$.

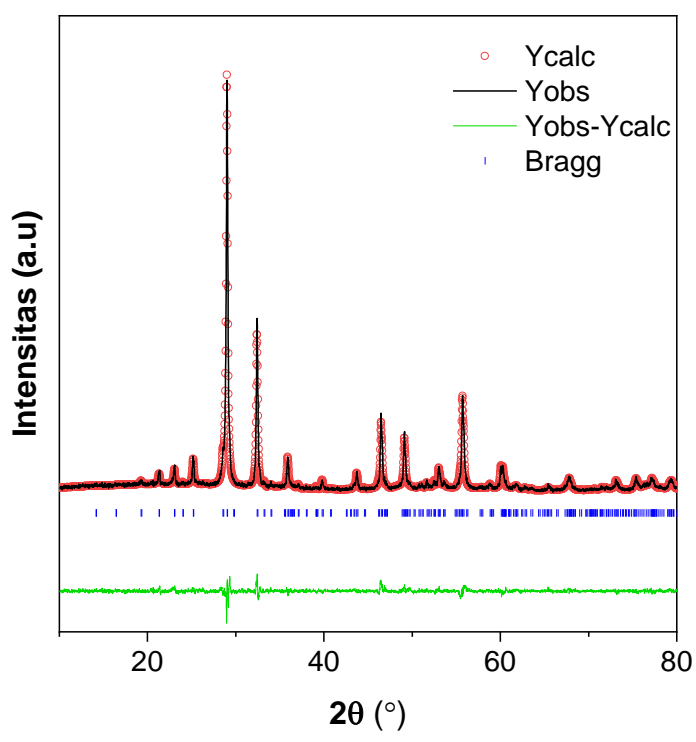

Gambar 2. Plot hasil refinement difraktogram SBT

Tabel 1. Data kristalografi SBT

\begin{tabular}{cc}
\hline Parameter & SBT \\
\hline Sistem kristal & Orthorombik \\
Grup ruang & $A 2_{1} a m$ \\
Unit azimetrik $(\mathrm{Z})$ & 4 \\
Panjang $a(\AA)$ & $5,5214(5)$ \\
Panjang $b(\AA)$ & $5,5238(8)$ \\
Panjang $c(\AA)$ & $25,0114(8)$ \\
Volume sel $\left(\AA^{3}\right)$ & $762,84(6)$ \\
$R_{p}(\%)$ & 20,5 \\
$R_{w p}(\%)$ & 19,8 \\
$G o F\left(\chi^{2}\right)$ & 3,1 \\
\hline
\end{tabular}

Morfologi sampel SBT ditampilkan pada Gambar 3. dan menunjukkan bahwa partikel SBT berbentuk plate-like dan dalam keadaan teraglomerasi. Bentuk plate-like merupakan bentuk khas dari senyawa Aurivillius [18]. Terbentuknya aglomerasi merupakan efek penggunaan metode sintesis reaksi keadaan padatan dikarenakan penggunaan suhu tinggi [19]. 
Hasil pengukuran luas area 5 partikel terpilih dirangkum pada Tabel 2 (partikel yang dihitung ditunjukkan pada Gambar 3) dan diperoleh hasil bahwa luas area partikelnya relatif besar pada rentang $0,127-0,758 \mu \mathrm{m}^{2}$, sehingga dapat dinyatakan bahwa ukuran partikelnya juga relatif besar.

Tabel 2. Luas area partikel SBT

\begin{tabular}{cc}
\hline Partikel & Luas area $\left(\boldsymbol{\mu m}^{2}\right)$ \\
\hline Partikel 1 & 0,758 \\
Partikel 2 & 0,348 \\
Partikel 3 & 0,313 \\
Partikel 4 & 0,334 \\
Partikel 5 & 0,127 \\
\hline
\end{tabular}

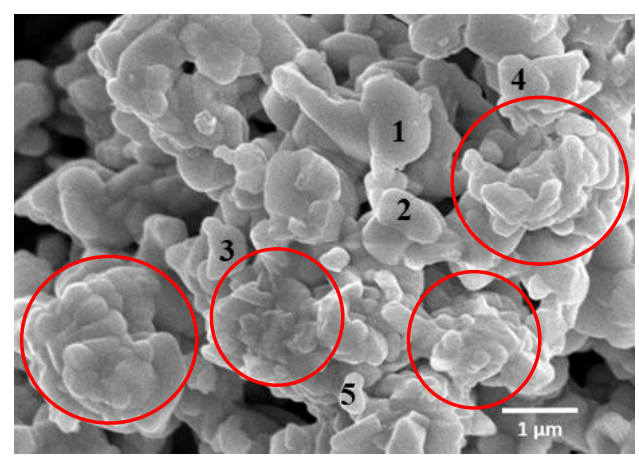

Gambar 3. Morfologi senyawa SBT (partikel yang dihitung ukurannya diberikan tanda nomor, sedangkan tanda circle warna merah menunjukkan partikel yang teraglomerasi)

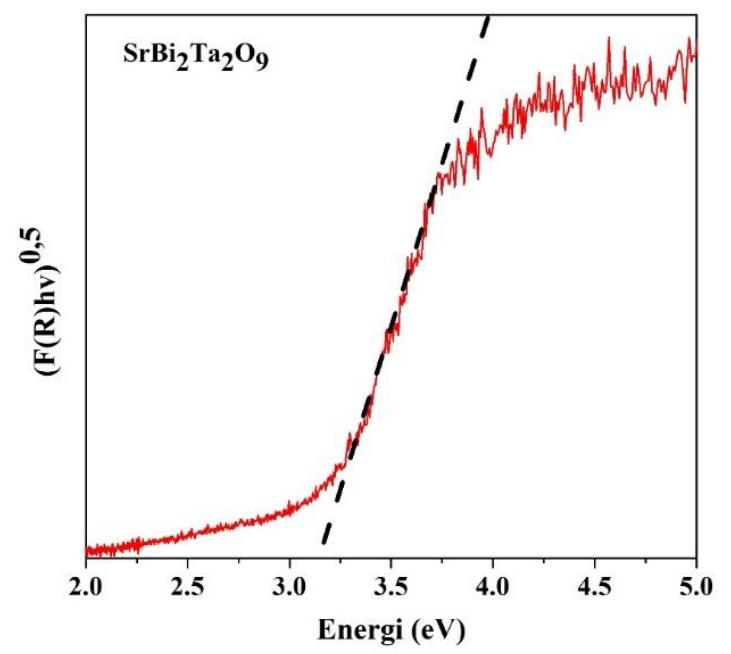

Gambar 4. Plot Tauc spektrum DRS senyawa SBT

Plot Tauc hasil perhitungan persamaan Kubelka-Munk ditampilkan pada Gambar 4. dan diperoleh hasil bahwa SBT mempunyai energi celah pita sebesar 3,15 eV (393,6 nm). Serapan energi pada panjang gelombang tersebut disebabkan oleh transisi elektronik dari orbital $2 p$ $\mathrm{O}$ dan $6 p$ Bi ke orbital $5 d$ Ta [16]. Nilai energi celah pita yang diperoleh menunjukkan bahwa senyawa ini masih bekerja pada daerah sinar ultraviolet.

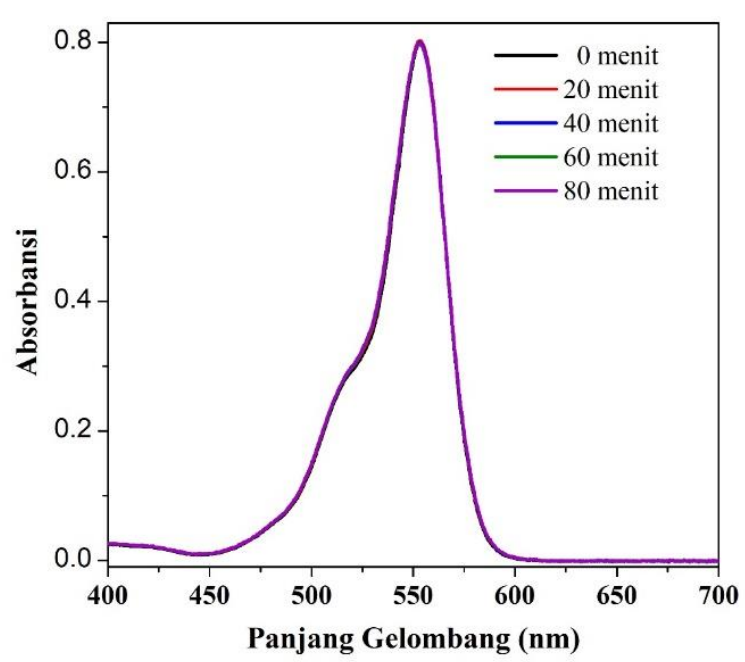

Gambar 5. Spektra absorbansi UV-Vis pada uji kestabilan RhB terhadap sinar UV

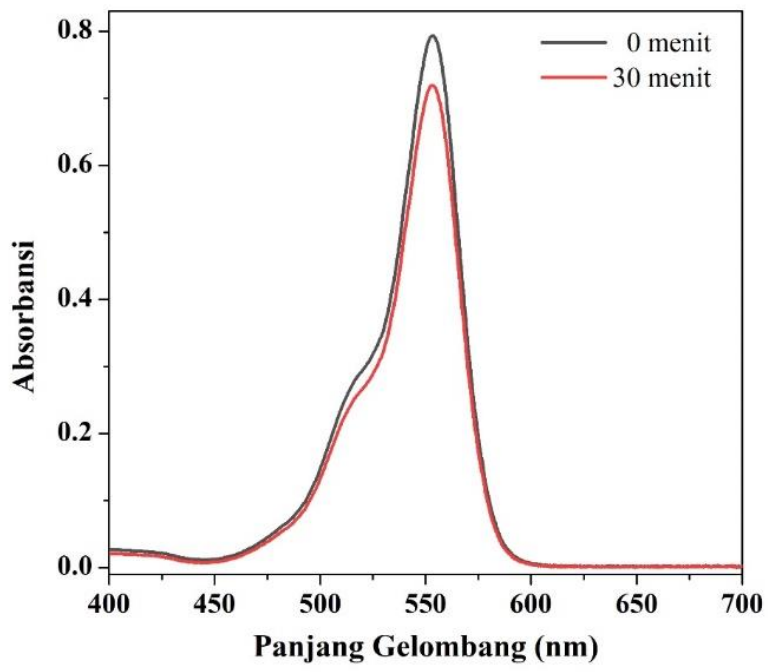

Gambar 6. Spektra absorbansi UV-Vis pada uji adsorpsi-desorpsi

Untuk mengetahui pengaruh sinar UV terhadap kestabilan larutan RhB maka dilakukan pengukuran konsentrasi RhB yang dipapar sinar UV. Spektrum UV-Vis sampel uji ditampilkan pada Gambar 5, dan diperoleh hasil bahwa nilai absorbansi yang relatif sama. Hal ini menunjukkan bahwa larutan RhB tidak terpengaruh oleh paparan sinar UV. Proses fotokatalisis terjadi pada permukaan material fotokatalis sehingga ada kemungkinan juga terjadi adsorpsi zat warna oleh material fotokatalis. 
Spektrum UV-Vis hasil uji adsorpsi-desorpsi ditampilkan pada Gambar 6. dan ditemukan penurunan absorbansi sebesar 7,4 \% yang mengindikasikan terjadi penurunan konsentrasi $\mathrm{RhB}$ sehingga dapat dinyatakan bahwa senyawa SBT mempunyai kemampuan menyerap (adsorpsi) RhB.

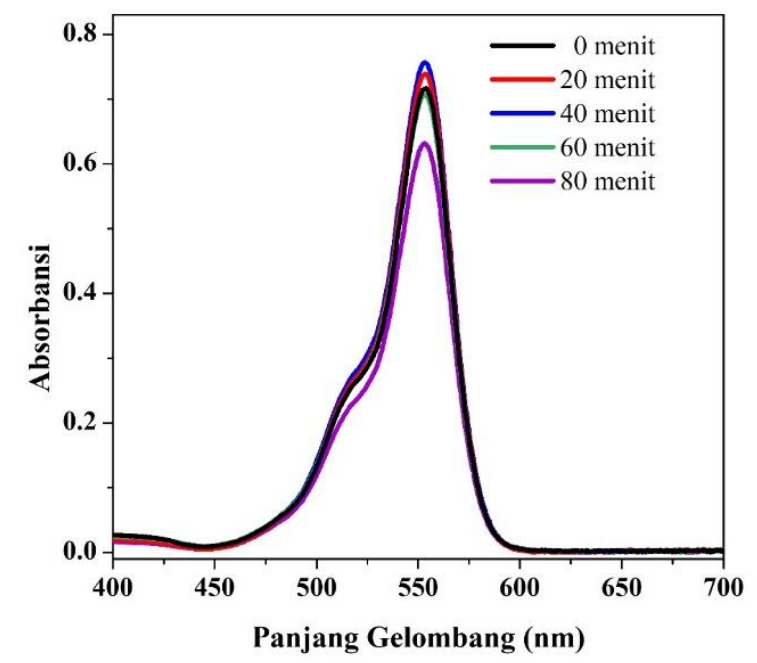

Gambar 7. Spektra absorbansi UV-Vis uji degradasi RhB oleh SBT

Hasil uji aktivitas fotokatalis ditampilkan pada Gambar 7. Pada 0; 20; 40 menit diperoleh nilai absorbansi yang sama, hal ini menunjukkan tidak adanya penurunan konsentrasi RhB. Penurunan absorbansi ditemukan pada waktu 60 dan 80 menit sebesar 1 dan $8,6 \%$ yang mengindikasikan bahwa konsentrasi $\mathrm{RhB}$ menurun karena terdegradasi oleh SBT. Kecilnya aktivitas fotokatalitik disebabkan oleh (a) partikel SBT dalam keadaan teraglomerasi dan menurut Pellgerino, dkk. (2017) menyatakan bahwa aglomerasi pada partikel fotokatalis dapat mengganggu proses penyerapan radiasi foton sehingga menyebabkan aktivitas fotokatalitiknya menurun [20]. (b) ukuran partikel SBT yang relatif besar sehingga luas permukaan yang semakin kecil, hal ini menyebabkan aktivitas fotokatalitik yang rendah [21,22]. Hasil aktivitas ini lebih kecil jika dibandingkan dengan dengan senyawa Aurivillius lapis tiga $\mathrm{Bi}_{2} A \mathrm{SrTi}_{2} \mathrm{TaO}_{12}(A=\mathrm{Bi}, \mathrm{La})$ yang dilaporkan oleh Wang, dkk., (2010) [23]. Hal ini disebabkan karena aktivitas fotokatalis dipengaruhi oleh beberapa faktor termasuk jenis kation $A$ dan $B[5,15]$.

\section{Kesimpulan}

Kemampuan Senyawa SBT dalam mendegradasi $\mathrm{RhB}$ adalah 8,6\% selama 80 menit. Kemampuan aktivitas fotokatalitik yang kecil dari
SBT dipengaruhi oleh aglomerasi partikel dan ukuran partikel yang relatif besar.

\section{Daftar Pustaka}

[1] Sundararajan M, Sailaja V, John Kennedy L, Judith Vijaya J. Photocatalytic degradation of rhodamine $\mathrm{B}$ under visible light using nanostructured zinc doped cobalt ferrite: Kinetics and mechanism. Ceram Int. 2017. 43(1):540-8. http://dx.doi.org/10.1016/j.ceramint.2016. 09.191

[2] Chen D, Cheng Y, Zhou N, Chen P, Wang $\mathrm{Y}$, Li K, et al. Photocatalytic degradation of organic pollutants using $\mathrm{TiO} 2$-based photocatalysts: A review. J Clean Prod. 2020.

268:121725. http://dx.doi.org/10.1016/j.jclepro.2020.1 21725

[3] Zhu D, Zhou Q. Action and mechanism of semiconductor photocatalysis on degradation of organic pollutants in water treatment: A review. Environ Nanotechnology, Monit Manag. 2019. 12:100255.

http://dx.doi.org/10.1016/j.enmm.2019.10 0255

[4] Xu C, Wei X, Ren Z, Wang Y, Xu G, Shen $\mathrm{G}$, et al. Solvothermal preparation of Bi2WO6 nanocrystals with improved visible light photocatalytic activity. Mater Lett. $2009 . \quad$ 63(26):2194-7. http://dx.doi.org/10.1016/j.matlet.2009.07 .014

[5] Wang W, Tadé MO, Shao Z. Research progress of perovskite materials in photocatalysis- and photovoltaics-related energy conversion and environmental treatment. Chem Soc Rev. 2015. 44(15):5371-408. http://dx.doi.org/10.1039/c5cs00113g

[6] Ding ZZ, Tang XQ, Ren JC, Liu XZ, Chen YK, Xia ZY, et al. Tuning the band gaps of ferroelectric Aurivillius compounds by transition metal substitution. Ceram Int. $2020 . \quad$ 46(6):8314-9. http://dx.doi.org/10.1016/j.ceramint.2019. 12.062

[7] Moure A. Review and Perspectives of Aurivillius Structures as a Lead-Free Piezoelectric System. Appl Sci. 2018. 8(1):62. http://dx.doi.org/10.3390/app8010062 
[8] DUBEY S, KURCHANIA R. Study of dielectric and ferroelectric properties of five-layer Aurivillius oxides: A2Bi4Ti5O18 $(\mathrm{A}=\mathrm{Ba}, \mathrm{Pb}$ and $\mathrm{Sr})$ synthesized by solution combustion route. Bull Mater Sci. 2015. 38(7):1881-9. http://dx.doi.org/10.1007/s12034-0151043-4

[9] Belver C, Adán C, Fernández-García M. Photocatalytic behaviour of Bi2MO6 polymetalates for rhodamine $\mathrm{B}$ degradation. Catal Today. 2009. 143(34):274-81.

http://dx.doi.org/10.1016/j.cattod.2008.09. 011

[10] Long M, Cai W, Kisch H. Photoelectrochemical properties of nanocrystalline Aurivillius phase Bi2MoO6 film under visible light irradiation. Chem Phys Lett. 2008. 461(13): $102-5$.

http://dx.doi.org/10.1016/j.cplett.2008.06. 081

[11] Xu L, Wan Y, Xie H, Huang Y, Qiao X, Qin L, et al. On Structure, Optical Properties and Photodegradated Ability of Aurivillius-Type

Bi3TiNbO9Nanoparticles. J Am Ceram Soc. $\quad 2016 . \quad 99(12): 3964-72$. http://dx.doi.org/10.1111/jace.14423

[12] Lu Y, Pu Y, Wang J, Qin C, Chen C, Seo HJ. On structure and methylene blue degradation activity of an Aurivillius-type photocatalyst of Bi4V2O11 nanoparticles. Appl Surf Sci. 2015. 347:719-26. http://dx.doi.org/10.1016/j.apsusc.2015.04 .164

[13] Handayani R, Safitri WN, Aini N, Hardian A, Prasetyo A. Synthesis and characterization of vanadium doped Bi4Ti3O12 as photocatalyst material. IOP Conf Ser Mater Sci Eng. 2019. 578:12017. http://dx.doi.org/10.1088/1757899x/578/1/012017

[14] Mamidi S, Gundeboina R, Kurra S, Velchuri R, Muga V. Aurivillius family of layered perovskites, BiREWO $6(\mathrm{RE}=$ La, Pr, Gd, and Dy): Synthesis, characterization, and photocatalytic studies. Comptes Rendus Chim. 2018. 21(5):547-52.

http://dx.doi.org/10.1016/j.crci.2018.01.0 11
[15] Li Y, Chen G, Zhang H, Li Z, Sun J. Electronic structure and photocatalytic properties of $\mathrm{ABi} 2 \mathrm{Ta} 2 \mathrm{O} 9(\mathrm{~A}=\mathrm{Ca}, \mathrm{Sr}, \mathrm{Ba})$. J Solid State Chem. 2008. 181(10):2653-9. http://dx.doi.org/10.1016/j.jssc.2008.05.0 20

[16] Tian Y, Zeng W, Liu Q-J, Liu Z-T. Theoretical Study of the Structural, Electronic, Chemical Bonding and Optical Properties of the A21 am Orthorhombic SrBi2Ta2O9. Brazilian J Phys. 2017. 48(1):25-30.

http://dx.doi.org/10.1007/s13538-0170544-6

[17] Swain S, Kumar P, Choudhary RB. Electrical and ferroelectric studies of the 2layered SrBi2Ta2O9 based ceramics. Phys B Condens Matter. 2015. 477:56-63. http://dx.doi.org/10.1016/j.physb.2015.08. 008

[18] Zhao Z, Li X, Ji H, Deng M. Formation Mechanism of Plate-like Bi4Ti3O12 Particles in Molten Salt Fluxes. Integr Ferroelectr. $2014 . \quad 154(1): 154-8$. http://dx.doi.org/10.1080/10584587.2014. 904705

[19] Marković S, Mitrić M, Starčević G, Uskoković D. Ultrasonic deagglomeration of barium titanate powder. Ultrason Sonochem. 2008. 15(1):16-20. http://dx.doi.org/10.1016/j.ultsonch.2007. 07.008

[20] Pellegrino F, Pellutiè L, Sordello F, Minero C, Ortel E, Hodoroaba V-D, et al. Influence of agglomeration and aggregation on the photocatalytic activity of TiO 2 nanoparticles. Appl Catal B Environ. $2017.216: 80-7$. http://dx.doi.org/10.1016/j.apcatb.2017.05 .046

[21] Li D, Song H, Meng X, Shen T, Sun J, Han W, et al. Effects of Particle Size on the Structure and Photocatalytic Performance by Alkali-Treated $\mathrm{TiO}(2)$. Nanomater (Basel, Switzerland). 2020. 10(3):546. https://pubmed.ncbi.nlm.nih.gov/3219742 1

[22] Xu N, Shi Z, Fan Y, Dong J, Shi J, Hu MZC. Effects of Particle Size of TiO2on Photocatalytic Degradation of Methylene Blue in Aqueous Suspensions. Ind Eng Chem Res. 1999. 38(2):373-9. http://dx.doi.org/10.1021/ie980378u 
[23] Wang D, Tang K, Liang Z, Zheng $\mathrm{H}$. Synthesis, crystal structure, and photocatalytic activity of the new threelayer aurivillius phases, $\mathrm{Bi} 2 \mathrm{ASrTi} 2 \mathrm{TaO} 12$ (A=Bi, La). J Solid State Chem. 2010. 183(2):361-6.

http://dx.doi.org/10.1016/j.jssc.2009.11.0 18 